\title{
IDENTIDADES, MEMÓRIA E ESPACIALIDADE NA FESTA DO ROSÁRIO
}

\author{
Patrício Pereira Alves de Sousa \\ Mestrando em Geografia pela Universidade Federal de Minas Gerais \\ Av. Antônio Carlos, 6627, Caixa Postal 719 - CEP 31270-901 - Belo Horizonte (MG), Brasil \\ Tel/fax.: (55 31) 3409-5409 - patricoalves@yahoo.com.br
}

\author{
Prof $^{\mathrm{a}}$. Dr ${ }^{\mathrm{a}}$. Marisa Barletto \\ barletto@ufv.br
}

\begin{abstract}
RESUMO
Este texto propõe algumas reflexões sobre a constituição de espaço e tempo social num distrito da cidade de Viçosa (MG) a partir da memória de seu grupo de Congado. A Festa do Rosário é aqui analisada como um re-fazer da paisagem local, a partir da apropriação, re-significação e também reprodução de lugares, que por sua vez são resultantes da disputa simbólica pela demarcação do espaço. Ao analisar a festa, entendemos que esta é carregada de simbolizações impressas no espaço, constituindo a paisagem e as relações de gênero, e que dão suporte à memória étnica e religiosa de parte dos afro-descendentes de Viçosa. Constatamos que o espaço funciona, na realidade analisada, como articulador de uma série de esferas que se amalgamam para configurar a festa como lugar de pedagogização de sujeitos. A noção de lugar festivo argumentada por Ferreira (2003), que sugere que o lugar festivo é uma das manifestações espaciais de conflitos que expressam o exercício do poder sobre o espaço através do discurso, elegendo-o como espaço da festa, permitiu que concluíssemos que a Festa do Rosário em São José do Triunfo acaba por produzir sujeitos e educações espaciais que transmitem saberes e técnicas intergeracionais e constrói/mantém identidades sócio-territoriais.
\end{abstract}

Palavras-chave: Memória, lugar, paisagem, festa, identidades.

\begin{abstract}
This text proposes some reflections on the constitution of social space and time in a district of the city of Viçosa (MG) starting from the memory of its group of Congado. The Festival of Rosário is considered here as a re-do of the local landscape, starting from the appropriation, re-significance and also reproduction of places, that are resulting of the symbolic dispute for the demarcation of the space. When analyzing the festival, we understood that this is loaded of symbolizations printed in the space, constituting the landscape and gender relations, and they give support to the ethnic and religious memory of the afro-descendants' festival of Viçosa. We conclued that the space works, in the analyzed reality, as an articulator of a series of spheres that merge to set up the festival as a place of pedagogization of subjects. The notion of place festive argued by Ferreira (2003), that suggests that the place festive is one of the space demonstration conflict that express the exercise of power on the space through the speech, electing him as the festival space, allowed us to conclude that the Festival of the Rosary in São José do Triunfo produces subjects and spatial educations. It transmits knowledge and techniques intergenerational and builds/maintains socio-territorial identities.
\end{abstract}

Key words: Memory, place, landscape, festival, identities.

\section{RÉSUMÉ}

Ce text propose quelques réflexions à propos de la constitution de l'espace et le temps social dans un district de la ville de Viçosa $(\mathrm{MG})$ à partir de la mémoire de son groupe du Congado. La fête du Rosaire est considéré ici comme un refaire du paysage local, à partir de l'appropriation, resignification et aussi reproduction des lieux, qui à leur tour sont le résultat d'une dispute symbolique par le délimitation de l'espace. Dans l'analyse de la fête, nous comprenons que cela est chargée des symbolisations imprimées dans l'espace, constituant le paysage et les relations de genre, et que maintient la mémoire ethnique et religieux d'une partie des afrodescendant de Viçosa. Nous constatons que l'espace fonctionne, dans la réalité analysées, comme articulateur d'une série de sphères qui se rassemblent pour mettre en place la fête comme un lieu de pedagogization de sujets. La notion de lieu festif soutenu par Ferreira (2003), qui suggère que le lieu festif est une des manifestations spatiales de conflits qui expriment l'exercice du pouvoir sur l'espace à travers du discours, l'élisant comme l'espace de la fête, nous a permis de conclure que la fête du Rosaire à São José do Triunfo produit des sujets et d'éducations spatiales qui transmettent des connaissances et des techniques intergénérationnels et construit/maintient identités socio-territoriales.

Mots-clés: Mémoire, lieu, paysage, fête, identités.

\section{Introdução}

Por toda Minas Gerais se espalham atualmente centenas de agrupamentos negros remanescentes da história colonial do estado que abrigou em seu espaço um dos mais bárbaros e vergonhosos ca-

Mercator - volume 8, número 17, 2009: set./dez. 
pítulos da história social de nosso país. As terras dos mais diversos rincões mineiros são matizadas com memórias dessa negritude, que nas favelas, periferias e áreas quilombolas buscam na contemporaneidade, através de inúmeras manifestações festivas, reavivar os percalços histórico-geográficos que levaram-na a ocupar as margens do sistema social vigente em nosso país que desprivilegia uma série de sujeitos que em seus corpos têm inscrita a condição afro. Sejam nas metrópoles ou nas mais interioranas das comunidades rurais mineiras, grupos de negros sustentam atualmente festejos que além de se constituírem em um de seus únicos momentos de lazer e divertimento, atuam como denúncia da violência material e simbólica contra os povos arrancados de África e jogados em terras americanas para na mais dura e penosa das posições sociais construírem a nação Brasil.

No presente trabalho buscamos problematizar a dimensão espaço-memorial fortemente existente num dos principais destes festejos negros presentes em Minas Gerais: as coroações de reis nas festas de Nossa Senhora do Rosário celebradas por grupos de Congado. Nossa análise se pauta na constituição de espaço e tempo social num distrito da cidade de Viçosa (MG) a partir da memória de sua irmandade de negros. A Festa do Rosário é aqui analisada como um re-fazer da paisagem local a partir da apropriação, re-significação e também reprodução de lugares, que por sua vez são resultantes da disputa simbólica pela demarcação do espaço. Ao analisar a festa, entendemos que esta é carregada de simbolizações impressas no espaço, constituindo a paisagem e as relações de gênero, e que dão suporte à memória étnica e religiosa de parte dos afro-descendentes de Viçosa.

\section{O CONGADO DE SÃO JOSÉ DO TRIUNFO}

O distrito de São José do Triunfo, localizado na cidade de Viçosa-MG, pertence à mesorregião da Zona da Mata Mineira. Lamas et al. (2007) informam que esta mesorregião ocupou significativa importância na história do Brasil por ter se configurado como a que provia grande parte dos suprimentos demandados pela região mineradora de Minas Gerais no auge do Brasil Colonial. Sua formação geográfica é, pois, em parte, fruto desta relação com as áreas auríferas de Ouro Preto e Mariana.

Com a decadência das minas de ouro na metade do século XVIII, efetivou-se na região a formação de fazendas com a base econômica orientada para a pecuária e as lavouras de café perpetuaram a condição escrava dos afro-descendentes.

O distrito de São José do Triunfo figurou-se neste cenário como importante território para a fixação de negros que se deslocaram junto de seus senhores das decadentes minas auríferas rumo à promissora região agropecuarista do Arraial de Santa Rita do Turvo, hoje a cidade de Viçosa. Segundo pesquisa realizada pelo $\mathrm{NIEG}^{1}$, alguns poucos moradores antigos ainda têm a memória da condição escrava. Segundo contam os moradores, São José do Triunfo tem o apelido de 'Fundão' porque o lugar era caminho de fuga de escravos, onde há uma grota que na época servia de refúgio; grota essa também chamada de 'Fundão'.

Paniago (1990) ressalta ainda que a população negra que se fixou nesta região é de origem do grupo Bantu, formada por inúmeras tribos do grupo Angola-Congolês e de grupos da ContraCosta. A autora apresenta como "evidência" da ocupação desta população na região de Viçosa as "sobrevivências culturais" encontradas por ela em pesquisas na década de 1980. Embora algumas outras manifestações desta cultura, como a dança jongo, ainda sejam evidentes, é, diz Paniago, nos grupos de Congos, Congadas ou Congados que é mais perceptível a presença do Bantu, sobretudo nos distritos de São José do Triunfo e de Cachoeira de Santa Cruz.

O Congado, como define Roberto (2000), é o termo que designa os cortejos de negros escravos que reverenciavam santos católicos em festas, rituais e cerimônias de coroação de Rei e Rainha Congo.

Os rituais do Reinado de Nossa Senhora do Rosário, ou Congado, constituem-se numa das mais importantes expressões da religiosidade e da cultura afro-brasileira presentes em Minas Ge- 
rais. O Reinado consiste num ciclo anual de homenagens a Nossa Senhora do Rosário e envolve a realização de novenas, levantamento de mastros, procissões, cortejos, coroações de reis e rainhas, cumprimento de promessas, leilões, cantos, danças, banquetes coletivos e a entrega de coroas. (MARTINS, 2002).

Ainda de acordo com Martins (2006), esta manifestação caracteriza-se como um sistema religioso que se hibridiza entre as orientações afro da religiosidade negra brasileira e o catolicismo popular de matriz européia. Durante as celebrações em torno da figura de N. Sra. do Rosário, os grupos de congo performatizam espacialmente, através de suas danças, cantos e celebrações, as travessias de negros da África para as Américas. Com suas narrativas mitopoéticas, os grupos consagram o espaço ao visitar lugares, ritualizando suas memórias de cativeiro, de travessia da África para o Brasil e de recordação do espaço além-mar. Estes grupos de congadeiros, ao celebrarem suas memórias, grafam no espaço, com seus corpos, a dramaturgia de passagem de uma condição de morte (escravidão, silêncio, imobilidade) para uma de vida (liberdade, resistência, voz e movimento). São criadas, desta maneira, geo-grafias memoriais.

Segundo os participantes mais antigos, a Festa do Rosário em São José do Triunfo começou por volta do ano de 1930, quando os avós dos atuais Rei Congo e Capitão da Banda levaram-na do centro da cidade de Viçosa para o distrito de São José do Triunfo (Fundão), data que coincide, segundo eles, com o início de formação deste distrito. Os atuais Rei Congo e Capitão da Banda - tidos pelos participantes do Congado como os que conservam o maior conhecimento da festa religiosa no local - transparecem em seus discursos e memórias sobre a festa uma indissociável relação entre o lugar, sua história e o Congado.

Nas falas desses participantes mais antigos - percebidos como "guardiões da memória" - as aproximações entre os distintos tempos por que passa o distrito, a festa e suas espacialidades são constantes. Isto é notório quando estes guardiões explicam a origem e o sentido do Congado. As referências ao espaço africano como local de procedência de um povo, de suas trajetórias e de suas crenças, são narrativas em tom de nostalgia e a espacialidade se expressa na recorrente necessidade de localização espacial de onde origina esta história. Parece mesmo haver por parte deles a necessidade de dar uma coerência aos percalços de suas raízes, onde um apontamento espacial torna-se fundamental. São feitas aproximações e conexões entre espaço e tempo para constituição da memória e dos sentimentos identitários e de pertencimento. Os guardiões entrevistados possuem forte relação com a história do distrito por estarem há um longo período nesta localidade e por serem "portadores" de um dos discursos que ocupam maior significação e centralidade sobre o lugar que habitam: o da Festa de Nossa Senhora do Rosário.

\section{ESPAÇO-FESTA}

A dimensão espacial no evento festivo do Congado envolve significações conferidas aos diversos símbolos expressos em termos de desenhos e inscrições territoriais por parte do grupo de dançadores e dos trechos percorridos durante os diversos momentos da festa, como alvoradas e procissões com a imagem de N. Sra. do Rosário. A estrutura coreográfica (ternos) possui uma série de sutilezas espaciais em sua organização, fruto da composição e encadeamento de movimentos, passos e gestos da dança de Congado. A festa, desta maneira, sendo um evento eminentemente de deslocamentos, faz-se e desfaz-se em constantes construções de imagens. A lógica da organização do grupo tem um grande sentido espacial, a banda de Congado e o Reinado são, em grande medida, um desenho repleto de sentidos. Corpo e espaço tornam-se um contínuo; o corpo é neste momento também paisagem e território e o espaço parte da estrutura física do indivíduo. 'Cortar' um terno é como ferir um corpo. Estas espacialidades também são expressas nas músicas entoadas pelos participantes da festa. Referências e alusões ao espaço da rua, ao continente africano e ao processo de abolição da escravatura no Brasil, são constituintes das cantorias. 
Vários autores no campo da Geografia Cultural (CORREAA, 2005; FERNANDES, 2003; FERREIRA, 2003; MAIA, 1999; dentre outros) têm discutido e pesquisado sobre a relação EspaçoFesta. Dentre as várias questões abordadas, destacamos a análise de Ferreira (2003), segundo a qual o lugar festivo seria uma das manifestações espaciais de conflitos que procuram exercer o poder sobre o espaço através do discurso, elegendo-o como espaço da festa. $\mathrm{O}$ ato de festejar teria, pois, uma dimensão eminentemente espacial, uma vez que controlar um dado espaço e concebê-lo como festivo por meio de tensões e conflitos pelo poder (no sentido foucaultiano) seria uma dimensão fundamentalmente do festar.

A delimitação do espaço da festa é pensada aqui a partir de constantes tensões que disputam um espaço simbólico. Travando-se batalhas retóricas, a 'conquista' dos lugares se definirá pelo domínio de suas significações e valores simbólicos. Desta maneira, é 'dono' do espaço aquele que detém o discurso e os saberes sobre ele. Assim, quem possui a memória da paisagem e do lugar, o domina, pois aquele que lembra é quem define o que deve ser lembrando e o que deve ser esquecido.

\section{ESPAÇO-MEMÓRIA}

As análises de Pollak (1989) convergem, de certa maneira, nesta mesma trilha de reflexão. Para o autor, a memória coletiva possuiria a função de avigorar os sentimentos de pertencimento de grupos e delinear as fronteiras entre coletividades. Em sua concepção, a alusão ao passado desempenharia o papel de sustentar a coesão das coletividades e das instituições que constituem uma sociedade, definindo seu lugar cabido, suas conexões, bem como seus conflitos. É o que o autor chama de enquadramento da memória, que teria por função 'produzir' a memória de modo a melhor se adequar para manutenção da identidade: os discursos e princípios sobre sua coerência e suas fronteiras. A memória teria, assim, o poder de tecer significações e sentidos aos lugares, uma vez que possui como herança as lembranças da formação e constituição dos espaços.

Neste sentido, podemos dizer que o ato de festejar se torna de fato festa quando se apropria dos lugares. Uma vez que a festa só existe enquanto disputa pelas significações que dão coerências e sentido em festejar para e sobre algo, e como muito bem define Ferreira, "a batalha retórica pela definição da festa só torna, na verdade, um afrontamento, ou seja, uma festa, quando a tensão se espacializa." (FERREIRA, 2003, p.12).

O que as pistas indicam é que a Festa de Nossa Senhora do Rosário chega ao Fundão num deslocamento gerado por batalhas discursivas ocorridas na área central do município. Segundo os "guardiões da memória", a festa antes de ocorrer no Fundão já acontecia em toda a região, inclusive em Viçosa, onde era organizada pelos avós dos "guardiões". O que supomos é que a festa étnico-religiosa tenha "perdido" a batalha retórica pelo lugar na área central da cidade. A figura 1 traz uma imagem de satélite de parte do município de Viçosa que dimensiona a atual localização do distrito de São José do Triunfo. A figura localiza ainda a área central da cidade, onde se estabelece seu poder administrativo e político-econômico; e a Universidade Federal de Viçosa, principal fixo da cidade responsável pela dinâmica localizacional do comércio e das especulações imobiliárias.

A pista principal sobre a perda da centralidade da festa dentro do contexto viçosense está na demolição da Igreja de N. Sra. do Rosário que havia na praça central do município, praça que hoje possui o nome de Praça do Rosário em função da Igreja que existiu naquele local até o início da década de 1960. Nos registros feitos em entrevistas há situações que corroboram com estas questões e explicam os motivos que ocasionaram a derrubada da Igreja:

A Rainha Conga era quem explicitamente comandava a fala, era ela quem dava rumo para a conversa, embora Eliana tentasse sempre acompanhá-la e fazer comentários em torno de suas falas.

Quando falaram no nome de Zé Felipe, começaram a falar dos convites que este fazia para que as pessoas fossem até Viçosa assistir o Congado. Neste momento começaram a falar da Igreja do Rosário que 
existiu em Viçosa, "e era uma Igreja petitinha do Rosário na Pracinha do Rosário". Eliana disse isto com tanta segurança que deu impressão de que ela havia conhecido a Igreja antes de ser derrubada, o que era improvável por sua idade, então questionei se ela havia conhecido a Igreja, ela respondeu com um ar de que não fazia a menor diferença ter visto ou não a Igreja para que esta estivesse em sua memória: “ - Não, o povo é que conta.” Dona Maria falou mais sobre a Igreja: “ - É, era uma Igreja pequenininha, feita de ripa. Lá tinha Santa Efigênia, São Benedito e a Senhora do Rosário".

Questionei sobre o motivo da derrubada da Igreja, Dona Maria disse que foi em função da construção da pracinha, por vontade do prefeito. Perguntei sobre o posicionamento do padre, Dona Maria respondeu que:

"Para deixar Viçosa mais bonita, né meu filho?! Pra deixar Viçosa mais bonita desmanchou a Igreja. Agora, cadê os santos que desapareceu tamém? Os santos desapareceu, porque Santa Efigênia e São Benedito você não sabe onde é que está. É preto, né!!! (risos dela). O Senhor dos Passos fica lá na Igreja dos Passos. A Nossa Senhora do Rosário diz que tá lá na Santa Clara, quem falou comigo é uma moça que mora lá, mas eu não tenho certeza.". (Trecho das falas proferidas durante o Mapeamento Histórico em realização ao DRP. Diário de Campo). ${ }^{2}$

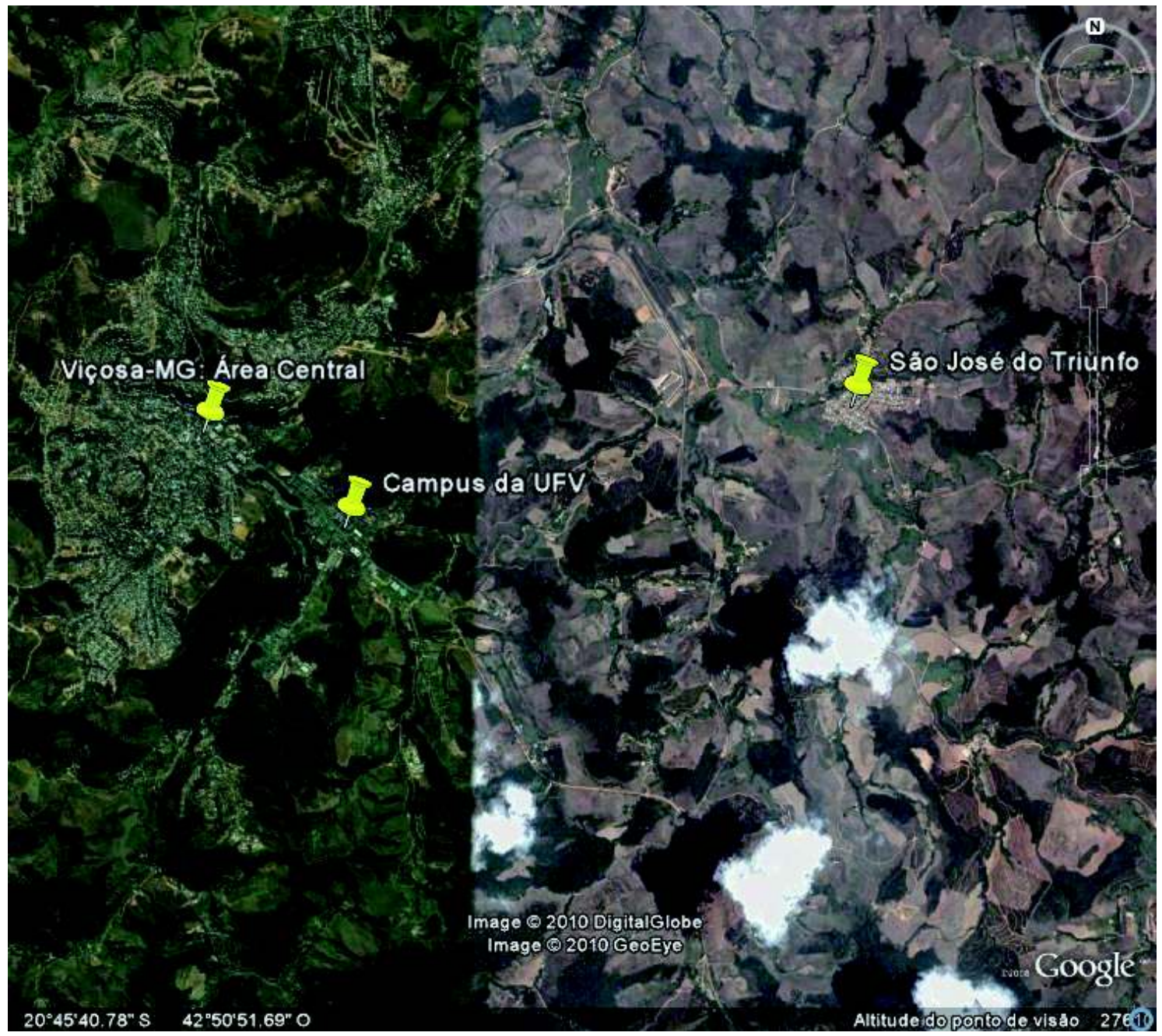

Figura 1: Imagem de Satélite do Município de Viçosa. ${ }^{3}$

As figuras 2 e 3 apresentam o mesmo espaço em dois contextos diferentes. A primeira retrata a Igreja do Rosário existente até o início dos anos 1960, a segunda apresenta a atual configuração paisagística da Praça do Rosário, espaço que abriga no centro da cidade grande parte do poder público da cidade de Viçosa. 


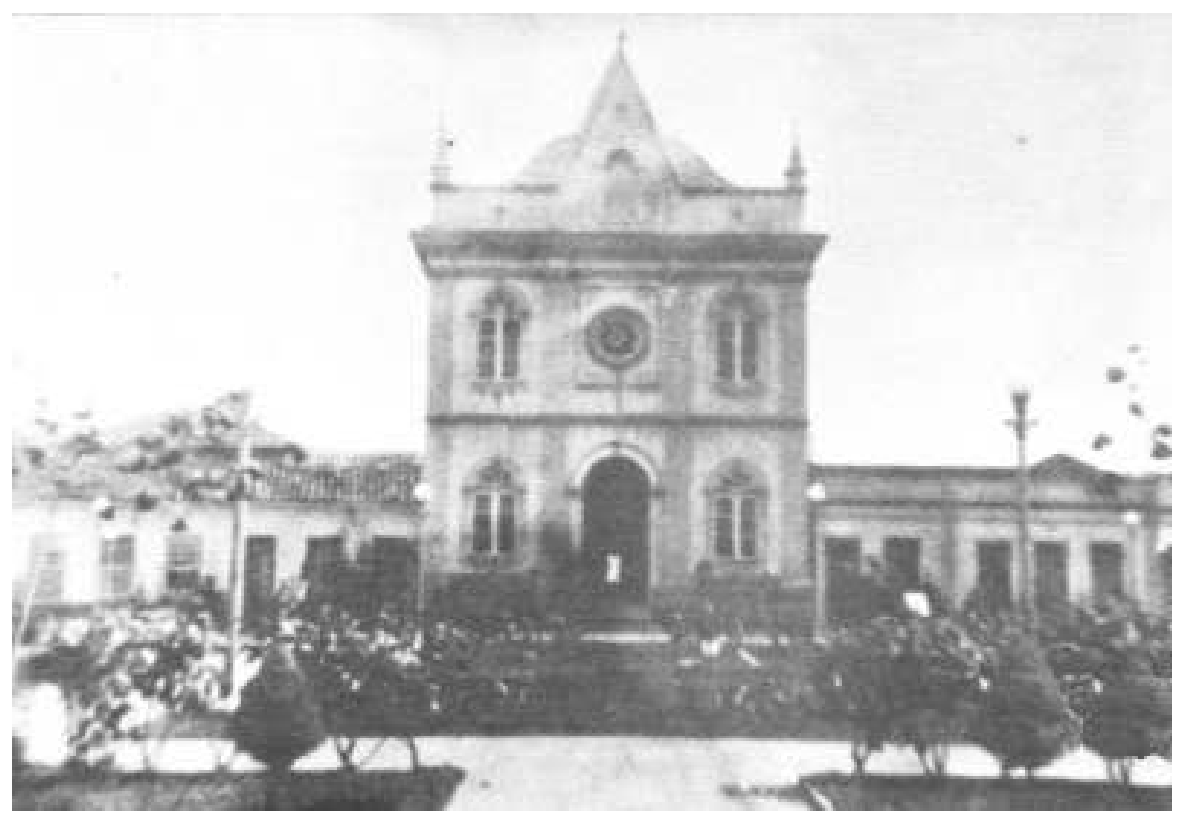

Figura 2: Igreja do Rosário no Centro de Viçosa demolida no início dos anos $1960 .{ }^{4}$

A fixação da Festa do Rosário no Fundão também não parece ter sido efetivada de forma muito tranqüila. Pelo relato dos "guardiões da memória", embora os festejos do Congado tenham se deslocado para o distrito em 1937, só recentemente a festa parece ter adquirido relações pacatas com a Igreja. A fala dos "guardiões" é emblemática neste sentido:

"Hoje em dia o povo dá muito mais valor, hoje o povo tem mais conhecimento do Congado. Isso aconteceu depois do Cônego ter aprendido em Ouro Preto sobre o Congado; quando o Cônego falou pro povo do Congado, o movimento passou a ter muito mais valor, o povo ganhou amor pelo nosso movimento." ( Fala de congadeiros registrada em diário de campo, 12/09/2006)

Para Pollak (1992), este processo de negociação da memória faz parte do processo de construção do sentimento de identidade. Seria a memória um elemento não só semelhante à identidade, mas constituinte desta, na medida em que se aproximam enquanto tentativa de negociação e da reconstrução de si.

Ninguém pode construir uma auto-imagem isenta de mudança, de negociação, de transformação em função dos outros. A construção da identidade é um fenômeno que se produz em referência aos outros, em referência aos critérios de aceitabilidade, de admissibilidade, de credibilidade, e que se faz por meio da negociação direta com os outros. Vale dizer que memória e identidade podem perfeitamente ser negociadas, e não são fenômenos que devam ser compreendidos como essências de uma pessoa ou de um grupo. (POLLAK, 1992, p.05)

Assim, o tempo vivido por um determinado grupo e as divisões impostas a ele são de cunho social, agindo inclusive sobre as memórias individuais, que se apóiam nestas divisões como marcos para sua lembrança. Junto do tempo, como dimensão da memória, figura-se o espaço como outra dimensão fundamental do lembrar-se. Pollak aponta que

Além dos acontecimentos e das personagens (...) existem lugares de memória, lugares particularmente ligados a uma lembrança, que pode ser uma lembrança pessoal, mas também pode não ter apoio no tempo cronológico. (...) Na memória mais pública, nos aspectos mais públicos da pessoa, pode haver lugares de apoio da memória, que são os lugares de comemoração. (...) Locais muito longínquos, fora do espaço-tempo da vida de uma pessoa, podem constituir lugar importante para a memória do grupo. 
(...) A memória da África, seja dos Camarões ou do Congo, pode fazer parte da herança da família com tanta força que se transforma praticamente em sentimento de pertencimento. (POLLAK, 1992, p.02-03).

E esta noção de espaço como aglomerador de estruturas temporais distintas é extremamente significativa para se entender a construção do lugar como a dimensão do espaço com o qual as pessoas estabelecem relações materiais de existência e construções simbólicas de identidade, pertencimento e, certamente, de memória.

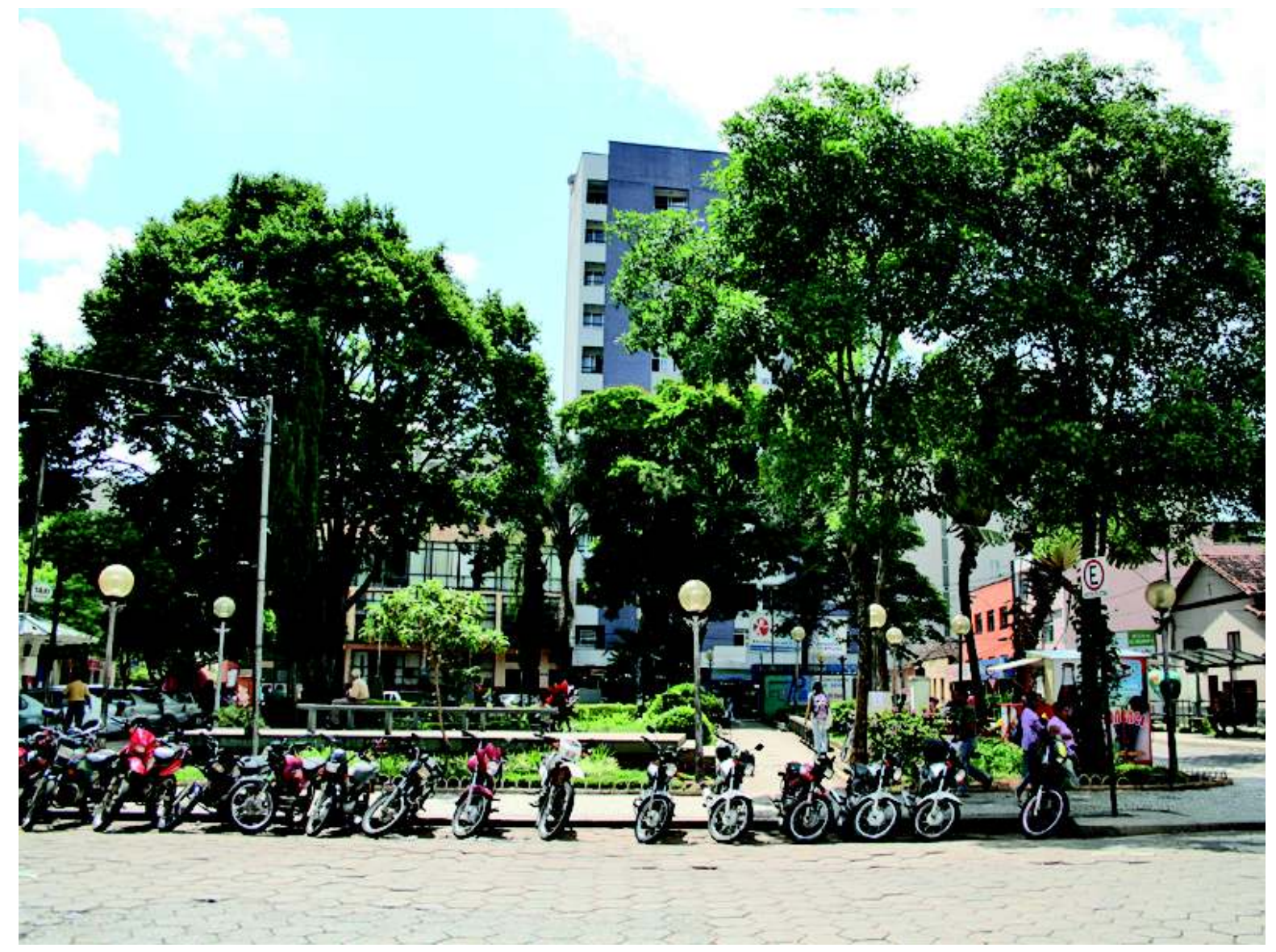

Figura 3: Atual Praça do Rosário. ${ }^{5}$

Isto nos leva a aproximação entre as paisagens e as memórias. As paisagens, enquanto referências maiores de um espaço e um tempo, podem transformar-se em memória na medida em que é necessário apoiar em cenários, ligados tanto a imagens, cheiros, sons e sabores que formam uma paisagem, para lembrar-se de algo. As lembranças retornam aos lugares, e é necessário, para tanto, retornar aos espaços que a memória tirou do movimento e transformou em formas com esforços de estatificação. Assim, o passado, para memorização, não pode ser tomado como fluxo, mas como lembrança de lugares e espaços vividos. (HARVEY, 2004).

É neste sentido que Holzer (1999) apresenta as concepções de Sauer, de que as paisagens não deveriam ser analisadas somente como uma cena que é vista pelo observador, mas pela complexidade que esta agrega. Seria a paisagem, neste sentido, cristalizadora dos conflitos entre os grupos que dividem mesmos espaços e da relação destes grupos com o espaço físico que habitam.

Este autor acrescenta ainda que a paisagem seria o resultado e cristalização do trabalho humano e das relações sociais, envolvendo um sentido cultural capaz de revelar traços do imaginário e das identidades impressas e constituintes destas. De acordo com Lowenthal, "as paisagens são formadas pelas preferências paisagísticas. As pessoas vêem seu entorno através das lentes da preferência e do costume, e tendem a moldar o mundo a partir do que vêem". (apud HOLZER, 1999, p.156). 
Nesse mesmo sentido, segundo Costa (2003), a materialidade constituinte da paisagem cria no indivíduo significações imateriais. A paisagem seria, neste ponto de vista, uma associação entre formas materiais visíveis e as lentes através das quais se olha estas formas, que pode remeter a uma imensidão de possibilidades, desde a identificação até a fobia e negação a um lugar.

Entendemos a noção de paisagem como formas materializadas no espaço dos diferentes tempos que se dão num mesmo local, fruto do trabalho e dos processos de socialização e conflitos de grupos, e como espaços repletos de símbolos e significações para os sujeitos e coletividades que fizeram parte de sua formulação ou que de alguma maneira tenham no presente algum contato com estas formas espaciais. Pensamos ainda a paisagem como formas permanentemente aptas à (re) construção e (re)significação pelas memórias e lembranças de pessoas que viveram estes lugares em diferentes tempos.

Halbwachs (1990) considera que, assim como se necessita colocar germes em meios saturados para que eles se cristalizem, é necessário trazer à memória estímulos para que ela se torne massa consistente de lembranças. Neste sentido compreende-se que a festa funciona como estímulo para lembranças de fatos coletivos outrora vividos. Paisagem e memória pensadas neste nível revelam a festa como evento propício para análise das memórias coletivas em torno da paisagem. A festa com seu poder pedagogizante, por possuir certa regularidade temporal e um caráter ritualístico e de repetição, fixa na memória de seus participantes e ensina aos novos integrantes do grupo seus valores e crenças, cria certas paisagens mentais e constrói a memória espacial do grupo a ela vinculado.

Embora já tenhamos salientado que a relação da Festa do Rosário com a Igreja Católica hoje aparenta conflitos, é importante fazer alguns apontamentos. São grandes as 'concessões' feitas pela Igreja ao momento festivo: ela 'permite' a substituição do pároco local por um padre negro na maior parte da missa, 'permite' que o grupo adentre no espaço da nave da Igreja batucando seus tambores e que os de maior hierarquia na festa ao fim da missa possam proferir seus dizeres, que em grande parte das vezes são enunciados em algo muito distante do português e muito mais próximo das línguas de origem africana. A relação apresenta, entretanto, uma série de sutis conflitos. Fica claro pela estruturação da missa que quem a dirige é a Igreja Católica, que 'concede' de acordo com sua 'permissão' voz ao grupo de congadeiros. A recíproca também se dá nesta dimensão. Embora o grupo de Congado professe claramente suas filiações cristãs, a missa é tomada de momentos que parecem se distanciar disso. As falas proferidas ao fim da missa caracterizam muito bem este fato, os congadeiros tiram totalmente o domínio da Igreja no momento em que começam a falar numa outra língua e num ritmo e tom que se aproxima significativamente de outras formas de culto religioso.

A festa da N. Sra. do Rosário - com seus hibridismos, sincretismos, sobreposições e outros movimentos - é, desta maneira, um re-fazer da paisagem local a partir da apropriação, re-significação e também reprodução de lugares, que por sua vez são resultantes da disputa simbólica pela demarcação do espaço. O distrito é re-desenhado, cartografado segundo outros referencias - dos afro-descendentes. A tradição - tradução - do Congado é um modo de, num mesmo golpe, restaurar referências étnicas e seus embates históricos no campo da religiosidade.

\section{ESPAÇO, PEDAGOGIA E PROCESSOS DE SUBJETIVAÇÃOO}

Paisagem e memória assim pensadas revelam a festa como evento propício para análise das memórias coletivas em torno da paisagem e dos lugares. Este sentido de festa como pedagogia, quer dizer, como evento social que trabalha na manutenção da memória de acontecimentos históricoculturais e de espaços, pode ser bem apreendido pela contribuição de Giacalone (1998). Esta autora defende a função educativa da festa como a de uma função pedagógica responsável por transmissões culturais, de saberes e técnicas intergeracionais.

Em Foucault (2005), também se é possível apreender, em grande medida, este sentido pe- 
dagogizante da festa. É mesmo creditado a este autor esta noção da pedagogia como processo de formulação de poderes que geram hierarquias e processos de construção de saberes nos grupos.

A função ou papel pedagógico, em Foucault, aparece em termos do adestramento, da regulação e da hierarquização, em suas proposições sobre as formas de poder disciplinar que rege nossas instituições e relações. Há na festa um poder disciplinar gerador de hierarquias criadas em termos de fiscalização do cumprimento de tarefas e padrões comportamentais que gera um ambiente de pedagogização. ${ }^{6}$

$\mathrm{Na}$ essência de todos os sistemas disciplinares, funciona um pequeno mecanismo penal. É beneficiado por uma espécie de privilégio de justiça, com suas leis próprias, seus delitos especificados, suas formas particulares de sanção, suas instâncias de julgamento. (...) Na oficina, na escola, no exército funciona como repressora toda uma micropenalidade do tempo (atrasos, ausências, falta de zelo), da maneira de ser (grosseira, desobediência), dos discursos (tagarelice, insolência), do corpo (atitudes 'incorretas', gestos não conformes, sujeira), da sexualidade (imodéstia, indecência). (FOUCAULT, 2005, p. 149).

Uma educação espacial e uma pedagogização de sujeitos são estabelecidas. A festa hierarquiza os participantes, sob a prerrogativa de que há distinções de saberes entre eles, num escalonamento de funções de acordo com os que possuem saberes acumulados sobre o funcionamento da festa e seus percalços num determinado lugar, e que se faz necessária a diferenciação de tarefas entre seus participantes com a justificativa de dar melhor organização ao evento.

A respeito das ritualizações da festa, que atuam como processo educativo, podemos apontar as orações a divindades constantes nos ensaios e encontros do grupo, os dizeres proferidos pelos de maior hierarquia e respondidos pelos demais e as músicas entoadas e os ritmos entrosados nos batuques da banda, como ações que cumprem o papel de manter uma série de imagens, sons, odores e sensações como pertencentes à festa. É como que um exercício de construção de déjà-vu, é a edificação de sistemas educacionais que alcançam sua eficácia pela garantia de internalização de valores, crenças, informações e saberes do grupo social pelo caráter repetitivo do evento festivo.

Em termos de pedagogia como regulação, podemos citar dois instrumentos que o grupo lança mão para construção de hierarquizações. Um é a lista de freqüências dos participantes nos ensaios. Há um detalhado fichário com a contagem de faltas dos membros do grupo, com o nome completo de todos os participantes e até a data de entrada e saída de todos os que participam ou já participaram do grupo. Todos têm clareza da autoridade desta lista de presenças: faltas causam o desligamento de membros do grupo.

A função de fiscais, responsáveis por ordenar a posição de todos os componentes no terno e chamar atenção dos mais dispersos na banda, é outro instrumento. As orientações durante o ensaio sobre posturas a serem tomadas, sobre o cuidado com a vestimenta e com os horários no dia da festa, o ensaio de alguns dizeres a serem proferidos por aqueles no topo da hierarquia na festa e respondidos pelos demais membros, corroboram essa análise.

As transmissões de saberes e ensinamentos entre gerações é outro traço pedagógico da festa. Há considerável participação de crianças no grupo e é grande a atenção dos mais velhos para com elas. Interessante também é a existência de funções desempenhadas especificamente por adolescentes e jovens, como as de secretário e vassalo mirim. As figuras 4 e 5 mostram adolescentes e crianças em festejo durante atividades do Congado. 


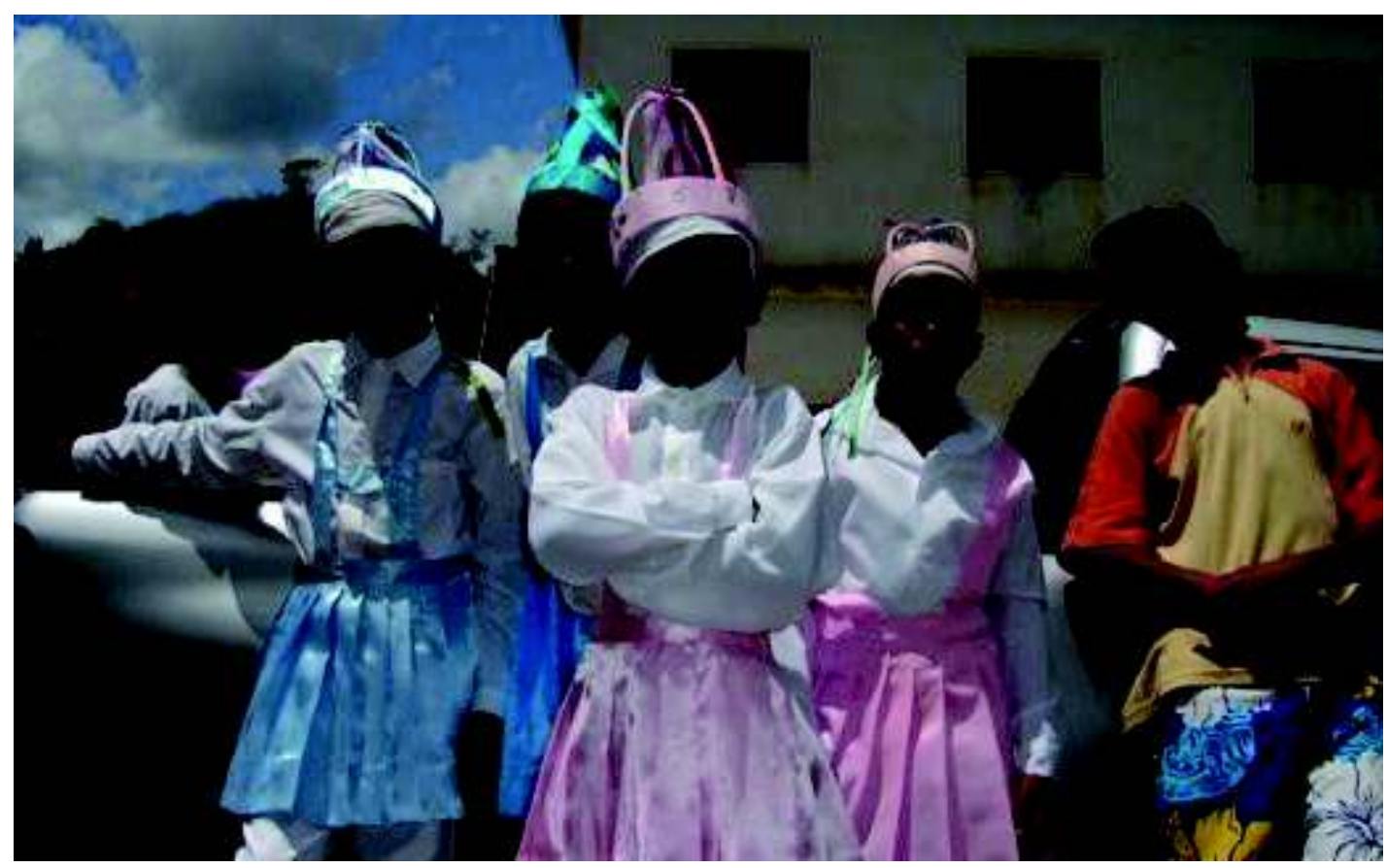

Figura 4: Crianças participantes da banda de Congado durante a Festa do Rosário do ano de 2006.

Durante o início das celebrações pela novena da festa do ano de 2007 foi possível presenciar uma cena que muito bem ilustra esta questão da transmissão de saberes e educação de novas gerações para a participação na Festa do Rosário e filiação à irmandade de negros no distrito. A cena foi descrita em diário de campo e é reproduzida abaixo:

\begin{abstract}
No momento em que eu observava a banda cantando esta música chegou perto de mim um homem que aparentava ter por volta de trinta anos. Este, ao dirigir-me a palavra disse: "Como é linda está coisa não é mesmo? Participar eu não participo, mas tudo que eu posso fazer para ajudar eles pela prefeitura eu faço, tava querendo até ver se eu fazia umas camisas pra eles este ano, mas não sei se vai dar." Até então este homem não tinha me dado chance de dizer nenhuma palavra, ele aparentava ser morador do distrito e ser bem próximo dos participantes da banda, também é negro e parece ter algum vínculo empregatício com a prefeitura. Resmunguei qualquer coisa concordando com a afirmação dele e ele prosseguiu: "E você pensar que tem pessoas entre 3 e 77 anos na banda, é uma coisa linda, e estes meninos então... Tem dias que não é período de Festa e estes meninos saem na rua, uns quase vinte, batucando numas latas e passeando por estas ruas tudo, diz que tão fazendo Festa." Depois disso ele se despediu de mim e disse que tinha de ir a um lugar qualquer. (Diário de Campo, 05/10/2007).
\end{abstract}

Esta passagem é indicativa de como a festa é eficaz no processo de incutir aos participantes mais jovens da banda os preceitos religiosos da Festa do Rosário e filosóficos da Irmandade. Neste caso, é nas brincadeiras infantis, momento de descontração e descompromisso de ações, que fica expresso como ocorre a transmissão intergeracional de saberes e memórias - as crianças brincam o modo de fazer o Congado.

\title{
ESPAÇO-IDENTIDADES
}

Há de se analisar ainda o caráter disciplinar do espaço festivo responsável pela educação de sujeitos na construção de suas identidades. As dimensões de gênero e etnia, neste sentido, logo nos saltaram aos olhos como dimensões sobre as quais é permanente e sutil a tentativa de gerar demarcações entre as diferenças entre sujeitos para que sejam firmadas suas identidades.

A tentativa da edificação/manutenção de identidades étnico-raciais se dá, sobretudo, a partir do esforço de se construir uma coesão à comunidade de negros do distrito. É possível observar em 
diversos momentos das festividades, como em cantorias ou danças, a maneira como o evento faz com que os indivíduos do grupo se liguem a referenciais comuns que remetem a uma memória de cativeiro e de consolidação da Irmandade de negros no distrito.

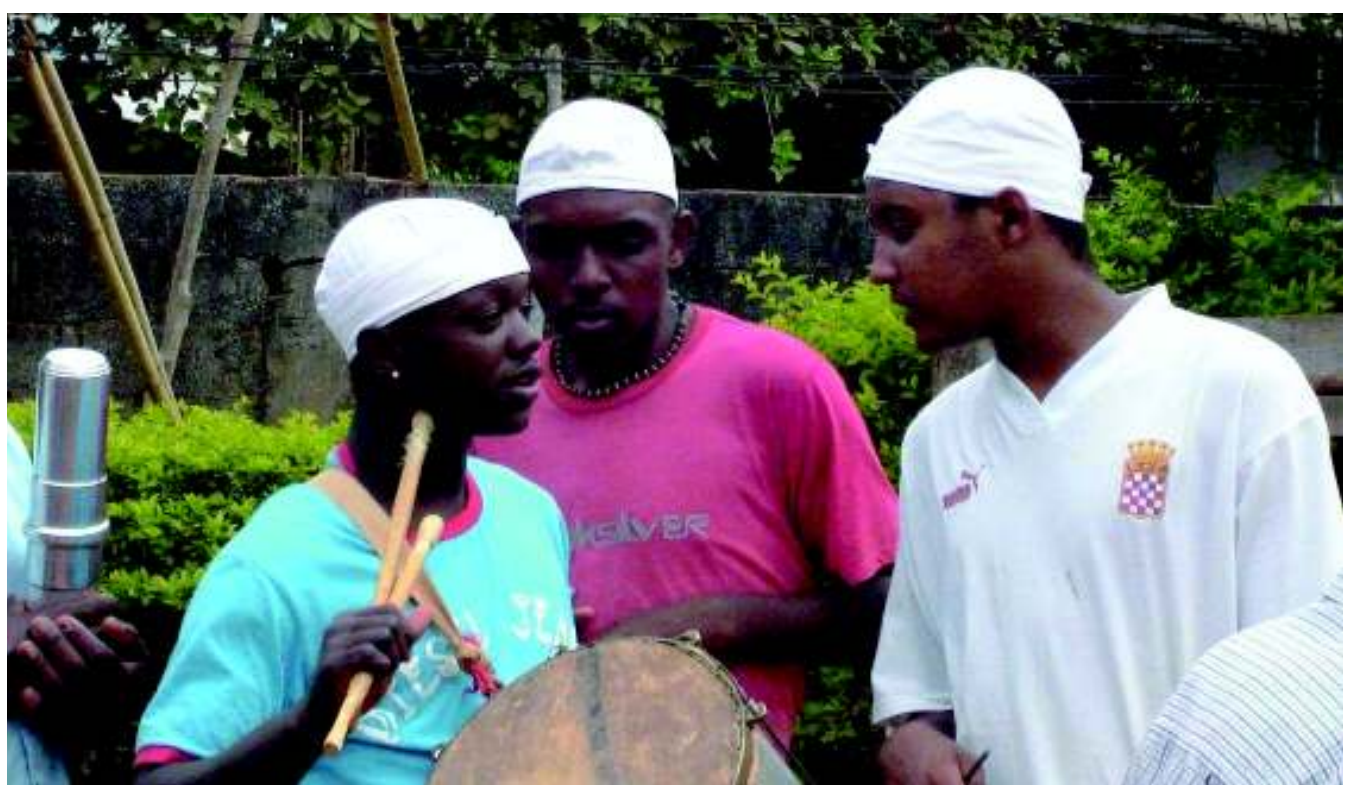

Figura 5: Adolescente em momento de ensaio para a Festa do Rosário.

As identidades étnico-raciais se constroem a partir da concordância entre os membros do grupo de especificidades que possuem em oposição às outras comunidades que compõem as relações sociais. Pudemos constatar que o grupo se enxerga enquanto singularidade a partir de suas particularidades ante as demais etnias existentes no Brasil, ante aos povos de histórias distintas que conformam a cidade de Viçosa e no distrito de São José do Triunfo e pelas expressões culturais que os dão status político diferenciado religiosamente. As falas dos membros do grupo buscam sempre salientar o que lhes é específico, para que possam ter assegurados os elementos que os unem. Isto tanto em termos da diferenciação em relação às demais etnias quanto em relação àquelas de orientação comum, mas que formam grupos distintos. A fala seguinte dos "guardiões da memória" dimensiona um pouco a questão:

Era constante também nas falas de Seu Zeca e Seu Dola a defesa das singularidades da Festa do Rosário no Fundão: "É o Congado diferente em cada lugar; ritmos, vestimentas... A diferença que tem de um pra outro é a dança (jogo de pé), instrumentos (tambores, caixas), batida, cantoria, fardas".

"Nosso Congado é religião, se só tem festa nós não estamos. Nosso Congado é uma irmandade e não uma associação. Associação, como a capoeira, tem patrocínio, nós não.” (Diário de Campo, 12/09/2006).

A construção deste sentimento de especificidade dos elementos que dão singularidade ao Congado de São José do Triunfo e, portanto, atuam na construção da identidade da Irmandade de negros do distrito, é formulada em grande medida pelo processo educativo realizado através das ferramentas ritualísticas da Festa do Rosário. São as músicas, por exemplo, que a todo o momento vêm relembrar a história do grupo, sua memória de cativeiro e de resistência; é o encontro anual em função da Festa que traz membros da Irmandade que moram a muitos quilômetros de distância do distrito e em apenas dois ou três dias de manifestação faz revigorar e manter nestes membros, hoje distantes da comunidade, seus sentimentos de pertencimento a um grupo e a um lugar.

Podemos, então, afirmar que o principal elemento assegurador das identidades étnico-raciais da população negra de São José do Triunfo é a Festa de Nossa Senhora Rosário, que funciona como elemento articulador dos diferentes tempos e espaços que a festa vive, atuando também em rearranjos 
dos elementos constituintes da identidade étnico-racial que passa continuamente por necessidades de rearticular seus elementos identitários.

As pedagogias de gênero também são formuladas nos mais distintos momentos da festa, a partir das tentativas de estabelecimento de lugares distintos para homens e mulheres, para o masculino e o feminino na estrutura do evento. (In)visibilidades e silêncios aí são produzidos numa constante tentativa de se estabelecer e evidenciar uma lógica masculina para a festa.

A Festa do Rosário em São José do Triunfo é um evento majoritariamente masculino em seus aspectos paisagístico. A presença exclusiva de homens na banda e nos espaços mais públicos das celebrações é indicativa desta questão. As transcrições de cenas do diário de campo apresentam mais a respeito desta idéia:

Nos fundos da casa se reunia também um grande número de pessoas, das quais grande parte eram mulheres envolvidas na feitura do café para momentos posteriores da festa. (Diário de campo, Festa de 12 pra 13, 12/05/2007).

Perguntei se todas iam a alvorada, Dona Maria respondeu que: “ - Nóis é os primeiro, a festa é nossa, uai." Daí Dona Ana e Dona Regina, falam por si. Disseram elas que passam toda noite acordadas com os preparativos da festa e que só vão dormir quando a alvorada já está saindo. Eliana diz querer dormir um pouquinho neste momento para não ficar com a cara muito feia, mas que não deixa de participar pelo menos um pouco. (Diário de campo, Diagnóstico Rápido Participativo - Mapeamento com Mulheres).

No início da alvorada o número de congadeiros e de acompanhantes da Festa ainda era bastante reduzido. A presença aí era sobretudo de mulheres, que como em nenhum outro momento anterior da Festa dançaram com tanta evidência. Os passos eram bastante extravagantes, com grandes deslocamentos em torno da banda e com muito riso. Não havia nenhuma criança e nenhum fiscal no início da alvorada. (Diário de campo, Alvorada da Festa do Rosário, 14/10/07).

Momentos antes da Festa, acabei por ficar junto a várias mulheres da família de Seu Dola. Num momento em que me encontrava junto à Cláudia (nora de Seu Dola) e mais uma moça, também da família, elas comentavam sobre a 'mancada' que deram próximo ao fiscal da banda ao dizerem que quem faz a alvorada na verdade são as mulheres, pois nesta hora os homens já estão cansados e são elas que sustentam o evento. (Diário de campo, Recesso da Festa do Rosário, 14/10/07).

Estas transcrições indicam alguns aspectos sobre as dimensões de gênero no Congado. As mulheres, pelo exposto, aparentam ter memórias das Festas distintas das dos homens. As paisagens por ela lembradas nem sempre estão relacionadas aos espaços públicos, já que os espaços por elas ocupados durante as festas muitas vezes são cozinhas, interiores de igrejas e cômodos de costuras. As figuras 6 e 7 apresentam mulheres em espaços da festa tidos como periféricos. 


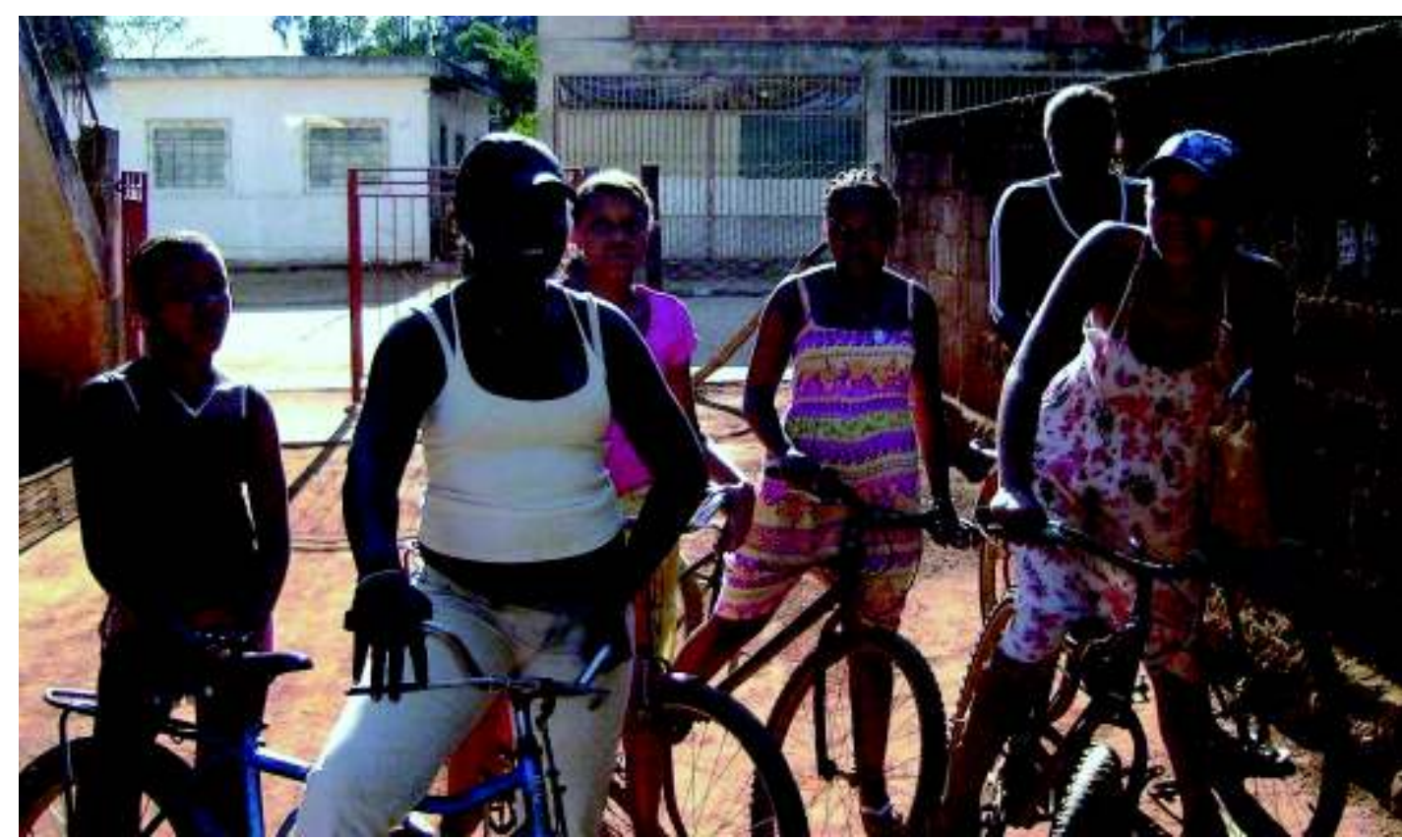

Figura 6: Meninas assistem ao ensaio de parentes e amigos homens.

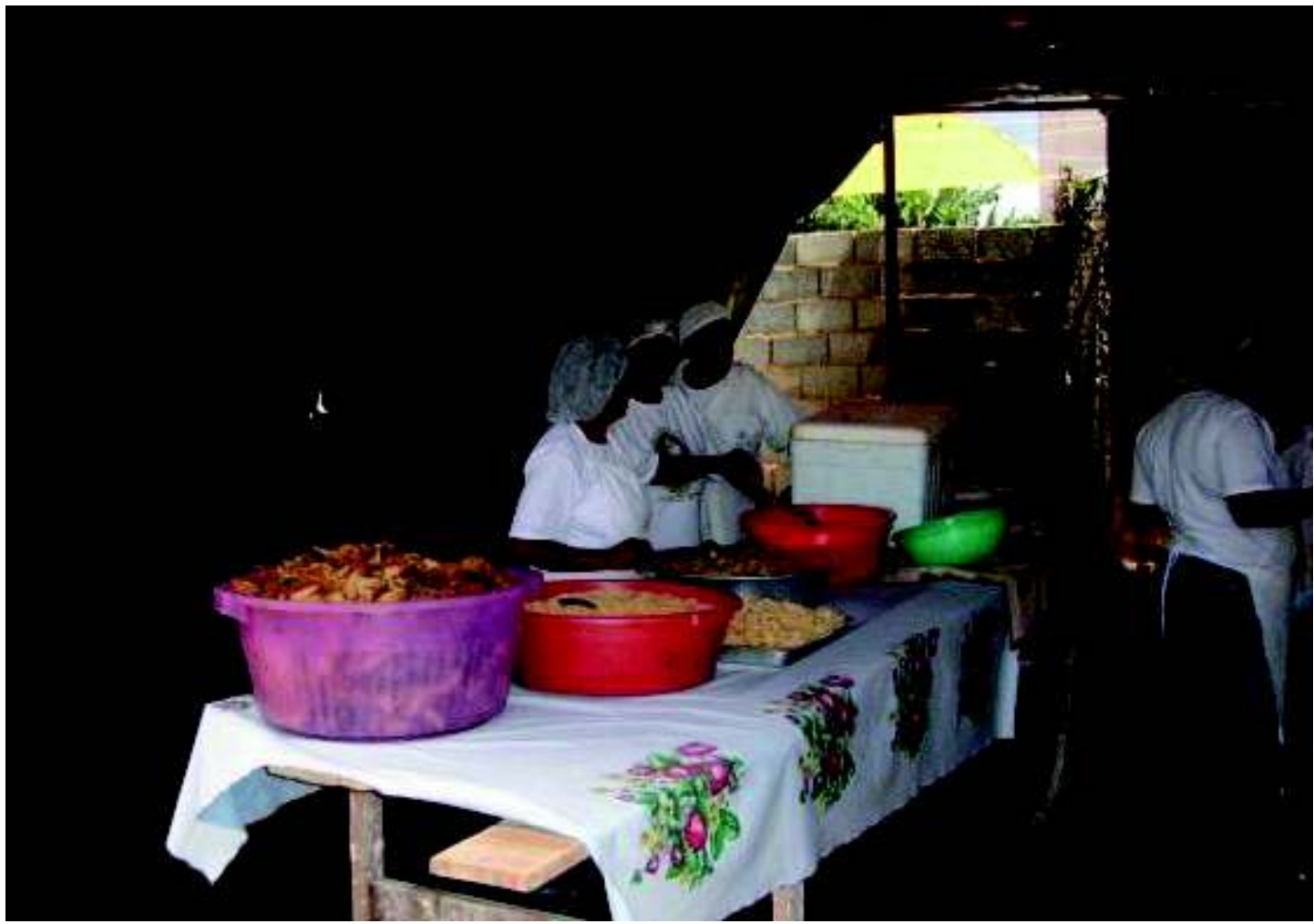

Figura 7: Mulheres preparam o almoço da festa

\section{CONSIDERAÇÕES FINAIS}

O espaço funciona, desta maneira, como articulador desta série de esferas que se amalgamam para configurar a festa como lugar de pedagogização de sujeitos. Festa, memória, tempo e espaço se fundem numa só dimensão para caracterizar o processo educativo de crianças, jovens e idosos, de homens e mulheres pertencentes à Irmandade de negros de São José do Triunfo.

Por sua vez, a utilização da noção de lugar festivo argumentada por Ferreira (2003), que sugere que o lugar festivo é uma das manifestações espaciais de conflitos que expressam o exercício 
do poder sobre o espaço através do discurso, elegendo-o como espaço da festa, permitiu que concluíssemos que a Festa de Nossa Senhora do Rosário em São José do Triunfo acaba por produzir sujeitos e educações espaciais que transmitem saberes e técnicas intergeracionais e constrói/mantém identidades sócio-territoriais.

Constatamos, dessa maneira, que o componente fundamental que baliza as identidades étnicoraciais da população negra de São José do Triunfo é a Festa de Nossa Senhora Rosário. E como já dito, não só numa perspectiva de manter a memória desta população situadas em tempos e espaços distantes, mas também na readequação e realização de novos arranjos aos percalços que o grupo passa em diferentes momentos e lugares. A Festa realiza e traduz processos históricos de interações simbólicas sobre o modo como as identidades produzem e mantêm o lugar da diferença nas representações de sujeitos de gênero e étnico-raciais. Essas relações históricas, depositadas no modo festar do lugar, espelham para seus participantes sua pertença, constituem referências culturais, cotidianas, repletas de religiosidade, referendando a produção de subjetividades. Seus dispositivos fundamentais são espaços e tempos traduzidos em Festa da Nossa Senhora do Rosário de São José do Triunfo, Viçosa, Minas Gerais, seja em sua particularidade, seja em sua universalidade.

\section{NOTAS}

(1) Trabalho de Extensão sobre Saúde Reprodutiva Feminina, realizado pelo NIEG - Núcleo Interdisciplinar de Estudos de Gênero - em 2000, junto aos agentes comunitários de saúde do PSF e da população feminina de São José do Triunfo, distrito de Viçosa-MG.

(2) O diário de campo consistiu num instrumental metodológico que nos permitiu a anotação dos relatos dos participantes do evento em questão realizados durante entrevistas de nossa pesquisa, bem como num exercício de descrição densa dos acontecimentos e das dinâmicas do distrito que observamos em acompanhamento ao grupo de Congado. Tal instrumento permitiu que fossem realizadas a apreensão das referências espaciais dos grupos em análise e o delineamento das tensões entre sujeitos participantes da festa e das simbolizações e conflitos realizados pelo/no lugar. Este diário de campo está publicado no site do Grupo Lux Festa do IESA/UFG e pode ser acessado pelo site $<$ http://www.iesa.ufg.br/festaspopulares/?menu_id=1225823911\&pos=esq\&site_id=49>

(3) Imagem extraída do Google Earth

(4) Fonte: BORGES, José Marcondes; SABIONE, Gustavo Soares. Primeiros Tempos da Universidade Federal de Viçosa. Viçosa: Ed. UFV, 2006. p. 69.

(5) Imagem disponível em: <http://www.alfahotel.com.br/imagens/fotosvicosa/Praca_do_Rosario_Vicosa_-_MG.jpg>, acesso em 19 nov. 2008.

(6) A pedagogização é uma expressão usada por Foucault para referir-se aos sistemas de controle, vigilância e punição organizados pelos discursos pedagógicos, constituindo um tecido normativo de subjetividades. Tal tecido normativo é acionado pelos dispositivos de saber, que podem ser jurídicos (normas de conduta institucional), científicos (sistemas de campos científicos) ou outros que se constituam como práticas discursivas de poder.

\section{REFERÊNCIA BIBLIOGRÁFICA}

CORRÊA, A. M. Não acredito em deuses que não saibam dançar: A festa do candomblé, território encarnador da cultura. In: CORRÊA, R. L.; ROSENDAHL, Z. (Org.). Geografia: Temas sobre Cultura e Espaço. Rio de Janeiro: EdUERJ, 2005.

COSTA, O. Memória e Paisagem: em busca do simbólico dos lugares. Espaço e Cultura, UERJ, Rio de Janeiro, v. 15, p. 33-40, jan./jun. 2003.

FERNANDES, N. da N. Geografia Cultural, Festa e Cultura Popular: limites do passado e possibilidades do presente. Espaço e Cultura, UERJ, Rio de Janeiro, v. 15, p. 23-32, jan./jun. 2003.

FERREIRA, L. F. O lugar festivo: a festa como essência espaço-temporal do lugar. Espaço e Cultura, UERJ, Rio de Janeiro, v. 15, p. 7-21, jan./jun. 2003.

FOUCAULT, M. Vigiar e punir: nascimento da prisão. 30. ed. Petrópolis: Vozes, 2005.

GIACALONE, F. Festa e percursos da educação intercultural. In: FLEURI, R. M. (org.). Intercultura e movimentos sociais. Florianópolis: Mover, NUP, 1998. p. 127-145. 
HALBWACHS, M. A memória coletiva. São Paulo: Vértice, 1990.

HARVEY, D. Condição pós-moderna: uma pesquisa sobre as origens da mudança cultural. 13. ed. São Paulo: Loyola, 2004.

HOLZER, W. Paisagem, Imaginário, Identidade: alternativas para o estudo geográfico. In: CORREAA, R. L.; ROSENDAHL, Z. (Orgs.). Manifestações da Cultura no Espaço. Rio de Janeiro: EDUERJ, 1999. p. 149-168.

LAMAS, F. G; SARAIVA, L. F.; ALMICO, R. C. S. A Zona da Mata Mineira: Subsídios para uma historiografia. Disponível em: <www.abphe.org.br/congresso2003/Textos/Abphe_2003_09.pdf>, acesso em 08 maio 2007.

MAIA, C. E. S. Ensaio interpretativo da dimensão espacial das festas populares: proposições sobre festas brasileiras. In CORREAA, R. L.; ROSENDAHL, Z. (Orgs.). Manifestações da Cultura no espaço. Rio de Janeiro: EdUERJ, 1999. p. 191-218.

MARTINS, L. M. Performances do tempo espiralar. In: ARBEX, M.; RAVETTI, G. (Orgs.). Performance, exílio, fronteiras, errâncias territoriais e textuais. Belo Horizonte: Faculdade de Letras da UFMG, 2002. p. 69-92.

MARTINS, L. M.. A oralitura da memória. In: FONSECA, M. N. S. (org.). Brasil afro-brasileiro. Belo Horizonte: Autêntica, 2006. p. 61-86.

PANIAGO, M. do C. T.. Viçosa - Mudanças sociais e socioculturais; evolução histórica e tendências. Viçosa: Imprensa Universitária, 1990.

POLLAK, M.. Memória, Esquecimento, Silêncio. Estudos Históricos, Rio de Janeiro, v. 2, n. 3, p. 03-15, 1989.

POLLAK, M. Memória e Identidade Social. Estudos Históricos, Rio de Janeiro, v. 5, n. 10, p. 200-212, 1992. ROBERTO, A. de P. A Festa de Nossa Senhora do Rosário no Serro, Minas Gerais: a reinvenção de uma tradição. Dissertação (Mestrado em Extensão Rural). Programa de Pós-Graduação em Extensão Rural, Departamento de Economia Rural, Universidade Federal de Viçosa, 2000.

Trabalho enviado em setembro de 2009

Trabalho aceito em dezembro de 2009 